\title{
Fatal Rift Valley Fever Outbreak Caused By Exposure To Meat From Sick And Dead Livestock: Uganda, July 2018
}

\section{Angella Musewa ( $\square$ musewaa@musph.ac.ug)}

Republic of Uganda Ministry of Health https://orcid.org/0000-0002-9399-1522

Bernadette B Mirembe

Republic of Uganda Ministry of Health

Alex R. Ario

$\mathrm{MOH}$ : Republic of Uganda Ministry of Health

Doreen Birungi

$\mathrm{MOH}$ : Republic of Uganda Ministry of Health

Lilian Bulage

$\mathrm{MOH}$ : Republic of Uganda Ministry of Health

Esther Kisaakye

Republic of Uganda Ministry of Health

Benon Kwesiga

Republic of Uganda Ministry of Health

\section{Steven N. Kabwama}

Republic of Uganda Ministry of Health

\section{David Muwanguzi}

Republic of Uganda Ministry of Health

\section{Daniel Kadobera}

Republic of Uganda Ministry of Health

\section{Steven Balinandi}

Uganda Virus Research Institute

Deo N. Birungi

National Disease Diagnostic and Epidemiology Centre

\section{Research}

Keywords: Rift Valley Fever, Outbreak, One Health, Global Health Security, Uganda

Posted Date: September 15th, 2021

DOI: https://doi.org/10.21203/rs.3.rs-853173/v1

License: () (1) This work is licensed under a Creative Commons Attribution 4.0 International License. Read Full License 


\section{Abstract}

Background: Rift Valley Fever (RVF) is a viral hemorrhagic fever that can be fatal to humans and livestock. During June-October 2018, reported RVF cases increased sharply in eight western and central Ugandan districts. We investigated to identify the scope of the outbreak, determine risk factors, and recommend control measures.

Methods: We defined a probable case as acute onset of unexplained fever with thrombocytopenia or leukopenia, plus $\geq 1$ of: unexplained bleeding, blurred vision, or unexplained death during June-October 2018 in a resident of the affected districts. A confirmed case was a probable case with a positive PCR test for RVF. We reviewed medical records and actively searched for cases in communities. In a casecontrol study, we compared exposures of cases and age-, sex-, and neighbourhood-matched controls. We reviewed livestock RVF surveillance data.

Results: We identified 19 cases (17 confirmed, 2 probable); 13 (68\%) died. The mean age of the case-patients was 36 (range: 27-55) years. The attack rate in men $(15 / 10,000)$ was 19 times higher than in women $(0.78 / 10,000)$. Stratified epidemic curves indicated multiple pointsource outbreaks, often following skinning/butchering livestock or eating grilled meat from livestock that had been sick or died of unknown causes ('sick/dead livestock'). All case-patients with data $(n=18)$ ate or butchered meat from sick/dead livestock. Of the 18 case-patients and 90 controls who participated in the case-control study, 10 case-patients (56\%) and five controls (5.6\%) cut or handled raw meat from sick/dead livestock $\left(\mathrm{OR}_{\mathrm{adj}}=14,95 \% \mathrm{Cl}=2.8-72\right)$. RVF-seropositive livestock were identified from serum samples taken from farms where human cases had occurred.

Conclusion. Human RVF outbreaks in Western and Central Uganda in 2018 were caused by contact with raw meat of sick/dead livestock. We recommended wearing protective gear during butchering, and safe handling and disposal of carcasses of sick/dead livestock. RVF surveillance data between human and livestock health sectors should be shared to facilitate early warning and detection for RVF.

\section{Introduction}

Rift Valley fever (RVF) is a zoonotic viral hemorrhagic fever (VHF) caused by the arthropod-borne RVF virus (1)(2). RVF is transmitted from infected animals to humans through handling of animal tissue, ingesting unpasteurized or uncooked milk of infected animals, and bites from infected Aedes mosquitoes (3)(4). Although disease in humans is often asymptomatic, a subset of patients develop hemorrhagic symptoms, with a case-fatality rate as high as $50 \%$ (6)(7). Early supportive treatment, including fluid replacement, is associated with improved outcomes and survival (8).

The first case of RVF was identified in 1931, among sheep on a Merino sheep farm in Rift Valley, Kenya during an unusually heavy rainfall season (9). Since that time, RVF cases have been reported in over 30 African countries (10). In Uganda, the first RVF case was reported in 1968 in livestock (11). In 2016, an outbreak occurred in Kabale District, Western Uganda, which affected both animals and humans (12). Subsequent outbreaks have been reported in Mityana and Kiboga Districts with both animal and human cases (13).

On 25 June 2018, Ministry of Health of Uganda received was notified about a 49-year-old male from Kasese district with confirmed RVF infection; the patient later died. Subsequently, the Ministry of Health received alerts about suspected RVF cases from ten additional districts. On 28 June 2018, a team of epidemiologists, entomologists, and veterinarians from the Ministry of Health (MOH), the Ministry of Agriculture, Animal Industry, and Fisheries (MAAIF), and the Uganda Virus Research Institute (UVRI) traveled to Kasese district to assess the scope of the outbreak, identify exposure factors, and recommend evidence-based control measures.

\section{Methods}

\section{Study area}

The outbreak occurred in eleven districts in western and central Uganda, including Kasese, Ibanda, Mbarara, Ntungamo, Isingiro, Sheema, Mubende, Rakai, Kiruhura, Sembabule, and Lyantonde Districts (Fig. 1). The affected districts are located in the "cattle corridor" of Uganda, where livestock-rearing is a major economic activity (14).

\section{Case definition and case finding}

We defined a suspected case as acute onset of fever $\left(>38^{\circ} \mathrm{C}\right)$ with a negative malaria test, and $\geq 2$ of the following symptoms: headache, myalgia, and any gastroenteritis symptom (nausea, vomiting, abdominal pain, diarrhoea) in a person from Mbarara, Sheema, Ntungamo, Kasese, Lyantonde, Rakai, Mubende, Isingiro, Sembabule, Kiruhura, and Ibanda districts from 1 June 2018 to 10 August 2018. A probable 
case was a suspected case with thrombocytopenia, low white blood cell counts, or elevated hematocrit plus at least one of the following: unexplained bleeding symptoms, such as bleeding from the nose, vomiting blood, coughing blood (without history of TB), blood in stool, blood in urine, sudden change in vision (e.g. blurred vision, poor vision, seeing floaters, pain in the eye, bilateral orbital pain), jaundice, or any unexplained death in a person with an epidemiologic link to confirmed cases. A confirmed case was a suspected or probable case which tested positive for RVF nucleic acid by reverse-transcriptase polymerase reaction (RT-PCR) (15).

We performed a record review at Mbarara Regional Referral Hospital and other health facilities in the affected districts. The main variables for which data were collected included fever $\left(\geq 37^{\circ} \mathrm{C}\right)$, vomiting, headache, and diarrhoea. We conducted a community case search with the help of community health workers. We conducted case investigations using a standard VHF data collection form, and collected additional information related to the patients' illness (16).

Additionally, for case-patients who were butchers, abattoir workers, and meat dealers, we asked about the sources of meat they purchased.

\section{Descriptive epidemiologic analysis}

We conducted a descriptive epidemiologic analysis of the cases by time, person, place, and symptoms. The population data for the descriptive epidemiologic analysis were obtained from each district's headquarters.

\section{Hypothesis generation}

We interviewed a convenience sample of 13 case-patients (or, for those that had died, their next-of-kin) who sought care at Mbarara Regional Referral Hospital about their possible exposures. We conducted an initial environmental assessment, where we observed grilled meat being sold on the streets of the eleven affected districts and butchering of dead livestock with little inspection.

\section{Case-control study}

We conducted a case-control study to test the hypotheses generated. A control was a person who had no fever from 1 June 2018 to the time of investigation. For each case, we randomly selected five neighborhood controls, individually matched by sex. Since all cases were adults ( $\geq 19$ years in age), we only selected adult controls.

We administered a structured questionnaire to case-patients/next-of-kin and controls to collect information on demographic characteristics (age, sex, and occupation) and potential exposures during the case-patients' effective exposure periods. We defined the effective exposure period to be 2-6 days before the case-patients' onset of fever (i.e., between the minimum and maximum incubation period for RVF) (17).

\section{Laboratory investigations}

We collected $5 \mathrm{ml}$ of blood from 17 of the 19 case-patients who survived to hospitalization. Samples were taken at the health facilities where the case-patients were being managed and were transported to the Uganda Virus Research Institute for PCR testing. PCR was performed on the RNA extractions to identify RVF virus using the TaqMan assay (18). RVF primers were designed from published GeneBank sequences, and applied using the established methodology (19). Additionally, as part of its livestock RVF surveillance effort, the Uganda National Animal Disease Diagnostic and Epidemiology Centre (NADDEC) collected serum specimens from livestock (goats, cattle, and pigs) in farms where human RVF virus infections were occurring, to test for RVF-specific lgM antibodies using an Enzyme Linked Immunosorbent Assay (ID Screen® Rift Valley Fever Competition Multi- species ELISA. Montpellier, France) (15).

\section{Environmental assessment}

At sites where human cases were identified, we assessed for the presence of livestock that had died suddenly during June-August 2018. We interviewed 35 village local leaders and 18 farmer cooperatives to understand more about how livestock meat was transported, the conditions and hygienic practices at local slaughterhouses, and animal movement and trading between different geographic areas.

\section{Data analysis}

To account for the matched study design, we used conditional logistic regression to estimate the odds ratios and their associated $95 \%$ confidence intervals, with the matching variable being the matched case-control set. At all levels of the analysis, this was applied for both bivariable and multivariable analysis.

\section{Results}




\section{Descriptive epidemiology}

We identified 19 case-patients, including 17 confirmed and 2 probable cases. Two of the probable case-patients died before hospitalization: clinical data were unable to be established for one, who was found dead on the roadside with severe hemorrhaging but who had an epidemiological link to confirmed cases in Ntungamo. This patient was a known butcher in Sanga (Kiruhura district) and reportedly purchased meat regularly from Ntungamo market, where four confirmed cases were working.

Of the 19 case-patients, 13 died (case-fatality rate $=68 \%$ ). The average time to death from symptom onset was 8 days (range, 5-15 days). Of the 13 deceased patients, 11 (85\%) sought care, with an average time from symptom onset to care-seeking of 7 days. In comparison, all six (100\%) surviving patients sought care, with an average time from symptom onset to care-seeking of 2 days. Among the 18 patients with symptom data, common symptoms included fever (100\%), lethargy (94\%), vomiting (72\%), epistaxis (67\%), diarrhoea $(67 \%)$, headache, hematemesis, and jaundice (52\% each) (Table 1). For the 18 cases with onset data, the epidemic curve shows continuous transmission of RVF infections (Fig. 2).

Table 1

Frequency of symptoms among 19 RVF case-persons during an outbreak in Uganda, June-August 2018

\begin{tabular}{|c|c|c|}
\hline Symptom & Frequency $(n=18)$ & Percent (\%) \\
\hline Fever & 18 & 100 \\
\hline Lethargy & 17 & 94 \\
\hline Vomiting & 13 & 72 \\
\hline Epistaxis & 12 & 67 \\
\hline Diarrhoea & 12 & 67 \\
\hline Headache & 10 & 56 \\
\hline Hematemesis & 10 & 56 \\
\hline Jaundice & 10 & 56 \\
\hline Abdominal pain & 9 & 50 \\
\hline Conjunctival bleeding & 9 & 50 \\
\hline Dehydration & 9 & 50 \\
\hline Hematuria & 9 & 50 \\
\hline Melena & 9 & 50 \\
\hline
\end{tabular}

The case-patients ranged in age from 27 to 55 years. Persons aged $25-39$ had a higher attack rate (AR) than persons $40-59$ years $(A R=$ 33 vs 13/10,000, $p=0.0001$. Men were 19 times as likely to be affected as women ( (Table 2). Of the 11 districts affected, Isingiro District, with seven cases, was the most affected $(A R=13 / 10,000)$ (Fig. 1). 
Table 2

Attack Rates by sex and age group during the RVF outbreak in Uganda June-August 2018.

\begin{tabular}{|llll|}
\hline Variable & Frequency $(\mathbf{n = 1 9 )}$ & Population & Attack Rate/10000 \\
\hline Sex & & & \\
\hline Female & 1 & 12,846 & 0.78 \\
\hline Male & 18 & 12,160 & 15 \\
\hline Age group & & & \\
\hline $0-24$ & 0 & 16,253 & 0 \\
\hline $25-39$ & 15 & 4,502 & 33 \\
\hline $40-59$ & 4 & 3,001 & 13 \\
\hline $60+$ & 0 & 1250 & 0 \\
\hline Total & 19 & 25,006 & 7.6 \\
\hline
\end{tabular}

Five (26\%) case-patients were butchers, five (26\%) abattoir workers / slaughterers, and three (16\%) were meat dealers. Of these 13 casepatients with meat-related occupations, $10(77 \%)$ reported that they purchased their meat for home consumption from a central market in Isingiro district, where meat was reportedly cheaper than in other markets.

\section{Hypothesis generation}

In hypothesis generation interviews, nine (69\%) of 13 case-patients/next-of-kin interviewed ate meat from sick animals and eight (62\%) cut meat from sick/animals. We therefore hypothesized that exposures to meat from sick/dead animals caused the outbreak.

\section{Case-control study findings}

We analyzed associations between various exposures to meat or tissue of livestock that had died of unknown causes (skinning/butchering dead/sick livestock, handling uncooked livestock meat, cutting meat of dead/sick livestock, eating grilled meat of dead/sick livestock, and handling livestock abortus).

The 18 patients for whom we were able to ascertain data were included in the case-control study. Cutting/handling meat from sick/dead livestock eating grilled meat from livestock that died suddenly, and touching uncooked livestock meat were associated with illness (Table $3)$. 
Table 3

Risk factors for Rift Valley fever during an outbreak in Uganda, June-August 2018

\begin{tabular}{|c|c|c|c|c|}
\hline Exposures & $\begin{array}{l}\% \\
\text { cases }\end{array}$ & $\begin{array}{l}\% \\
\text { controls }\end{array}$ & $\begin{array}{l}\text { OR }(95 \% \\
\mathrm{Cl}) *\end{array}$ & $\begin{array}{l}\text { ORadj }+(95 \% \\
\text { Cl) }\end{array}$ \\
\hline & $(n=$ & $(n=90)$ & & \\
\hline Butchered meat of livestock that died of an unknown cause (1) & 56 & 5.6 & $21(4.6-98)$ & $7.5(2.4-23)$ \\
\hline Ate grilled meat of livestock that died of an unknown cause (2) & 61 & 18 & $\begin{array}{l}6.7(2.3- \\
25)\end{array}$ & $8.6(2.4-31)$ \\
\hline $\begin{array}{l}\text { Cut/Handled meat from sick animals/livestock that died of an unknown } \\
\text { cause (3) }\end{array}$ & 59 & 34 & $3.8(1.2-$ & $2.8(1.0-8.1)$ \\
\hline \multicolumn{5}{|l|}{$3+2$} \\
\hline & 67 & 21 & $\begin{array}{l}7.5(2.5- \\
23)\end{array}$ & $4.0(1-16)$ \\
\hline \multicolumn{5}{|l|}{$3+1$} \\
\hline & 61 & 35 & $\begin{array}{l}2.9(1.0- \\
8.3)\end{array}$ & $3.1(1.0-9.6)$ \\
\hline \multicolumn{5}{|l|}{$1+2$} \\
\hline & 82 & 42 & $\begin{array}{l}6.6(1.8- \\
24)\end{array}$ & $13(2.8-63)$ \\
\hline \multicolumn{5}{|l|}{$1+2+3$} \\
\hline & 78 & 41 & $5.0(1.5-16)$ & $5.7(1.6-21)$ \\
\hline \multicolumn{5}{|c|}{ * $\mathrm{OR}=$ Unadjusted odds ratio from conditional logistic regression; $\mathrm{Cl}=$ confidence interval. } \\
\hline \multicolumn{5}{|l|}{${ }^{\dagger} \mathrm{OR}_{\mathrm{adj}}=$ Adjusted odds ratio from conditional logic regression. } \\
\hline
\end{tabular}

\section{Laboratory and environmental investigation findings}

All 17 human blood samples taken tested positive for RVF. Of the samples from 100 livestock taken from thirteen farms where human RVF infections occurred, 72 tested positive.

We conducted assessments at 18 sites where human cases were lived or worked. During interviews with 18 farmer cooperatives in the affected districts, 22 (52\%) reported that livestock on their farms had died recently; the carcasses had been butchered and the meat was shared and sold around villages. After the outbreak was reported, police checkpoints were set up in the affected districts to identify and stop any illegal trade of meat from animals that died of unknown causes. However, police reported that some butchers were able to evade the checkpoints by traveling during times when the checkpoints were not functioning, or by hiding meat in packages not typically used to transport meat.

\section{Discussion}

Our field investigation revealed the largest RVF outbreak in the past 50 years in Uganda. The outbreak occurred primarily in the "cattle corridor" of Uganda, and was associated with exposure to meat from livestock that died suddenly.

Exposure to meat from infected animals or exposure to abortus has been well-documented as a risk factor for RVF infection among humans in several studies in Africa and the Middle East (20)(21)(22)(23)(24)(25). Men are often more affected than women due to the frequency of their exposures, as was seen during this outbreak (22)(26). Younger adults were also more affected than older adults, likely due to differential participation in butchering and slaughtering activities. 
Isingiro district, which borders Tanzania and Rwanda, was more affected than other districts. In addition, the majority of case-patients reported purchasing their meat from Isingiro District, reportedly because it was more economical than purchasing it elsewhere. During the time this outbreak was occurring, Rwanda, which borders five of the affected districts including Isingiro, was experiencing an epizootic with suspected RVF cases reported (27). While it is unknown what started this outbreak, animal trade and movement between countries may have played a role. Isingiro also has a central abattoir where livestock are slaughtered and meat was distributed to the neighbouring areas, which could potentially have spread the infection, as well as a high cattle density, which has been associated with RVF outbreaks previously (28).

Beyond handling of meat, eating grilled meat from animals that died of unknown causes was also a risk factor in this outbreak, as in previous outbreaks (29)(25). Opportunities to eat meat in Uganda may be rare for poor communities, and depend on price of meat. Although animals that are sick or die of unknown causes are required by Ugandan regulations to be inspected by a qualified veterinarian before butchering, this does not always happen in practice. Instead, meat from sick livestock is often sold outside of official lanes, and more cheaply ( \$1 USD per kilogram) than meat from healthy animals ( \$4 USD per kilogram). In the area of Uganda where the outbreak occurred, residents typically grill chunks of meat on open fire; often the outside is burned, while the inside is still raw, which can facilitate transfer of infection to humans (30). In areas where RVF is a risk, the public should be educated about these risks and understand the need for complete cooking of meat. In addition, enforcement of regulations about slaughter of uninspected livestock need to be strengthened.

The case-fatality rate during this outbreak was high compared to previous outbreaks. High case-fatality rates for RVF have previously been associated with delays in seeking medical care (31)(26)(23). In this outbreak, patients who died were less likely to have sought care than surviving patients, and their average delay in care-seeking was longer than that of surviving patients. Persons working in high-risk occupations and living in areas where RVF occurs should receive education on the signs and symptoms of RVF infection, and the importance of early care-seeking for survival.

Currently, an inactivated RVF vaccine has been developed for human use (32). However, this vaccine is not licensed and is not commercially available. In animals, several live attenuated vaccines have been developed, and are meant for use in RVF-endemic regions (33). Although Kenya currently vaccinates all livestock against RVF, this is not carried out in Uganda, Rwanda, or Tanzania (34). Periodic and reactive vaccination could be employed strategically to effectively reduce the incidence of RVF outbreaks (35). An evaluation of the cost-effectiveness of livestock RVF vaccination in Uganda, either nationwide or in specific hotspots, would be helpful to inform policy.

Collaborations between animal, human, and environmental health partners (One Health approach) are key in rapid detection, response, and prevention of zoonotic outbreaks. However, optimizing these collaborations remains a work in progress. During this outbreak, early communication from animal health partners to human health partners about livestock sampling results could potentially have allowed intensified and focused risk communications to the populations at risk. Collective efforts among different partners in the entomologic and environmental fields as well as human health fields could also facilitate group decision-making on issues such as vector control, potentially reducing other mechanisms of RVF spread.

\section{Conclusion}

This RVF outbreak was caused by physical exposure to raw meat or eating meat from infected livestock. We recommended health education to the public on the dangers of handling and eating meat from livestock known to be sick or found dead, and the importance of thorough cooking of meat. We also recommended to adopt a One Health approach for effective control of RVF outbreaks. Specifically, partners should work under the existing One Health platform, coordinated by a central body, through which data can be shared in real-time and response activities can be discussed and planned together by partners from multiple areas of health expertise (36). This can both improve efficiency of resource use and reduce the number of areas affected. We further recommended that the Ministry of Agriculture, Animal Industry and Fisheries conduct routine surveillance for RVF in livestock and enforce rules and regulations regarding meat inspection.

Based on our findings, the district health offices conducted radio talk shows in the affected communities to sensitize them on the dangers of eating meat from animals that are sick or have died of unknown causes. The local governments of the affected districts also strengthened meat inspection by deploying meat inspectors at border sites as well as several meat-selling markets for the next three months.

\section{Abbreviations}

Page $7 / 12$ 
AR-Attack Rates, CDC-Centers for Disease Control and Prevention, RVF-Rift Valley Fever, Cl-Confidence Interval, UVRI-Uganda Virus Research Institute, OR-Odds Ratio, WHO-World Health Organization, RNA-Ribonucleic acid, RT-PCR-Real Time-Polymerase Chain Reaction, IgG-Immunoglobulins G, IgM- Immunoglobulins M

\section{Declarations}

\section{ACKNOWLEDGEMENTS}

We thank the Mbarara Regional Referral Hospital team, Isingiro district team and Ibanda Hospital for managing patients and providing clinical information during the investigation. We appreciate the support and assistance provided by all fellows and supervisors of the Uganda Public Health Fellowship Program during the investigation. We appreciate the Uganda Virus Research Institute for testing all samples and the timely release of results.

\section{Funding}

This project was supported by the President's Emergency Plan for AIDS Relief (PEPFAR) through the US Centers for Disease Control and Prevention Cooperative Agreement number GH001353-01 through Makerere University School of Public Health to the Uganda Public Health Fellowship Program, MoH.

\section{Disclaimer}

The findings and conclusions in this report are those of the author(s) and do not necessarily represent the official position of the Centers for Disease Control and Prevention, Makerere University School of Public Health, or the MoH. The staff of the funding body provided technical guidance in the design of the study, ethical clearance and collection, analysis, and interpretation of data and in writing the manuscript.

\section{Availability of data and materials}

The data that support the findings of this investigation belong to the Uganda Public Health Fellowship Program and are not available in publicly available repositories due to ethical concerns. However, the data can be accessed upon reasonable request from the corresponding author and with permission from the Uganda Public Health Fellowship Program.

\section{Author contributions}

AM, BBM, ARA, DB, LB, EK, BK, SNK, DM, DK, SB, and DNB conceived and designed the study. AM, BBM, DM, EK, BK, DM and SNK contributed to data collection, cleaning, and analysis. AM, BBM and DB implemented the study. AM and DK analyzed the data. AM, BBM, and DNB took lead in writing the manuscript. AM, BBM, ARA, DB, LB, EK, BK, SNK, DM, DK, SB, and DNB participated in manuscript writing to ensure scientific integrity and intellectual content. All authors contributed to the final draft of the manuscript. All authors read and approved the final manuscript.

\section{Ethical clearance and consent to participate}

This investigation was in response to a public health emergency (RVF outbreak) and was therefore determined by the US Centers for Disease Control to be non-research and that its primary intent was public health practice or a, epidemic or endemic disease control activity. The MoH Uganda through the office of the Director General of Health Services gave the directive and approval to investigate this outbreak. We obtained verbal informed consent from case-persons during this investigation and other interviewed community members that were above 18 years. We ensured confidentiality by conducting interviews in privacy ensuring that no one could follow proceedings of the interview. The questionnaires were kept under lock and key to avoid disclosure of personal information of the respondents to members who were not part of the investigation.

\section{Consent for publication}

Not applicable

\section{Competing interests}

Authors declare no competing interests 


\section{References}

1. Joseph K. 25 found dead in four months. New Vision Uganda. 2018 Jun 8.

2. Ly HJ, Lokugamage N, Nishiyama S, Ikegami T. Risk analysis of inter-species reassortment through a Rift Valley fever phlebovirus MP-12 vaccine strain. PLoS One. 2017.

3. Peyre M, Chevalier V, Abdo-Salem S, Velthuis A, Antoine-Moussiaux N, Thiry E, et al. A Systematic Scoping Study of the SocioEconomic Impact of Rift Valley Fever: Research Gaps and Needs. Zoonoses and Public Health. 2015.

4. Tran A, Trevennec C, Lutwama J, Sserugga J, Gély M, Pittiglio C, et al. Development and Assessment of a Geographic KnowledgeBased Model for Mapping Suitable Areas for Rift Valley Fever Transmission in Eastern Africa. PLoS Negl Trop Dis. 2016.

5. WHO. Rift Valley fever. WHO. 2016.

6. LaBeaud AD, Muchiri EM, Ndzovu M, Mwanje MT, Muiruri S, Peters CJ, et al. Interepidemic Rift Valley fever virus seropositivity, northeastern Kenya. Emerg Infect Dis. 2008.

7. Laughlin LW, Meegan JM, Strausbaugh LJ, Moren DM, Watten RH. Epidemic rift valley fever in Egypt: Observations of the spectrum of human illness. Trans R Soc Trop Med Hyg. 1979.

8. Amy Hartman. Rift Valley Fever. Clin LAB Med. 2017;37(2):285-301.

9. Daubney R, Hudson JR, Garnham PC. Enzootic hepatitis or rift valley fever. An undescribed virus disease of sheep cattle and man from east africa. J Pathol Bacteriol. 1931.

10. Centers for Disease Control and Prevention, National Center for Emerging and Zoonotic Infectious Diseases (NCEZID). Division of High-Consequence Pathogens and Pathology (DHCPP) VSPB (VSPB). Rift Valley Fever Distribution Map [Internet]. [cited 2019 Jun 10]. Available from: https://www.cdc.gov/vhf/rvf/outbreaks/distribution-map.html.

11. Henderson BE, Mc Crae AWR, Kirya BG, Ssenkubuge Y, Sempala SDK. Arbovirus epizootics involving man, mosquitoes and vertebrates at lunyo, uganda 1968. Ann Trop Med Parasitol. 1972.

12. Shoemaker TR, Nyakarahuka L, Balinandi S, Ojwang J, Tumusiime A, Mulei S, et al. First laboratory-confirmed outbreak of human and animal rift valley fever virus in Uganda in 48 years. Am J Trop Med Hyg. 2019.

13. Charles Olaro. Rift Valley Fever (RVF) outbreak confirmed in Mityana and Kiboga Districts [Internet]. Kampala; 2017. Available from: https://reliefweb.int/sites/reliefweb.int/files/resources/Press Release - RVF OUTBREAK.pdf.

14. UBOS. National Population and Housing Census 2014. 2016.

15. Rowe AK, Bertolli J, Khan AS, Mukunu R, Muyembe-Tamfum JJ, Bressler D, et al. Clinical, Virologic, and Immunologic Follow-Up of Convalescent Ebola Hemorrhagic Fever Patients and Their Household Contacts, Kikwit, Democratic Republic of the Congo. J Infect Dis. 2009.

16. Shoemaker TR, Balinandi S, Tumusiime A, Nyakarahuka L, Lutwama J, Mbidde E, et al. Impact of enhanced viral haemorrhagic fever surveillance on outbreak detection and response in Uganda. The Lancet Infectious Diseases; 2018.

17. Centers for Disease Control and Prevention, National Center for Emerging and Zoonotic Infectious Diseases (NCEZID). Division of High-Consequence Pathogens and Pathology (DHCPP) VSPB (VSPB). Rift Valley Fever; Signs and Symptoms. In:

https://www.cdc.gov/vhf/rvf/symptoms/index.html [Internet]. 2013. Available from:

https://www.cdc.gov/vhf/rvf/symptoms/index.html.

18. Pang Z, Li A, Li J, Qu J, He C, Zhang S, et al. Comprehensive multiplex one-step real-time TaqMan qRT-PCR assays for detection and quantification of hemorrhagic fever viruses. PLoS One. 2014.

19. Garcia S, Crance JM, Billecocq A, Peinnequin A, Jouan A. Michele Bouloy and DG. Quantitative Real-Time PCR Detection of Rift Valley Fever Virus and Its Application to Evaluation of Antiviral Compounds. J Clin Microbiol. 2001.

20. Nyakarahuka L, de St. Maurice, Purpura A, Ervin L, Balinandi E, Tumusiime S. A, et al. Prevalence and risk factors of Rift Valley fever in humans and animals from Kabale district in Southwestern Uganda, 2016. PLoS Negl Trop Dis. 2018.

21. Nicholas DE, Jacobsen KH, Waters NM. Risk factors associated with human Rift Valley fever infection: systematic review and metaanalysis. Trop Med Int Health. 2014.

22. LaBeaud AD, Pfeil S, Muiruri S, Dahir S, Sutherland LJ, Traylor Z, et al. Factors Associated with Severe Human Rift Valley Fever in Sangailu, Garissa County, Kenya. PLoS Negl Trop Dis. 2015.

23. Al Azraqi TA, El Mekki AA, Mahfouz AA. Rift Valley fever among children and adolescents in southwestern Saudi Arabia. J Infect Public Health. 2013. 
24. Wilson ML, Chapman LE, Hall DB, Dykstra EA, Ba K, Zeller HG, et al. Rift Valley fever in rural northern Senegal: Human risk factors and potential vectors. Am J Trop Med Hyg. 1994.

25. Anyangu AS, Gould LH, Sharif SK, Nguku PM, Omolo JO, Mutonga D, et al. Risk factors for severe rift valley fever infection in Kenya, 2007. Am J Trop Med Hyg. 2010.

26. Lagare A, Fall G, Ibrahim A, Ousmane S, Sadio B, Abdoulaye M, et al. First occurrence of Rift Valley fever outbreak in Niger, 2016. Veterinary Medicine and Science. 2018.

27. WHO. Outbreaks and Other Emergencies [Internet]. 2018. Available from: https://reliefweb.int/report/world/who-afro-outbreaks-andother-emergencies-week-27-30-june-6-july-2018-data-reported-1700.

28. Olive MM, Chevalier V, Grosbois V, Tran A, Andriamandimby SF, Durand B, et al. Integrated Analysis of Environment, Cattle and Human Serological Data: Risks and Mechanisms of Transmission of Rift Valley Fever in Madagascar. PLoS Negl Trop Dis. 2016.

29. Woods CW, Karpati AM, Grein T, McCarthy N, Gaturuku P, Muchiri E, et al. An outbreak of Rift Valley fever in Northeastern Kenya, 199798. Emerg Infect Dis. 2002.

30. Fawzy M, Helmy YA. The One Health Approach is Necessary for the Control of Rift Valley Fever Infections in Egypt: A Comprehensive Review. Viruses. 2019.

31. Archer BN, Thomas J, Weyer J, Cengimbo A, Landoh DE, Jacobs C, et al. Epidemiologic Investigations into Outbreaks of Rift Valley Fever in Humans, South Africa, 2008-2011. Emerg Infect Dis. 2013.

32. Kortekaas J, Zingeser J, de Leeuw P, de La Rocque S, Unger H, Moormann RJM. Rift valley fever vaccine development, progress and constraints. Emerg Infect Dis. 2011.

33. Ikegami T. Rift Valley fever vaccines: an overview of the safety and efficacy of the live-attenuated MP-12 vaccine candidate. Expert Review of Vaccines. 2017.

34. Mercy Kahenda. County launches vaccination drive against Rift valley fever. 2018 Aug 6; Available from: https://www.standardmedia.co.ke/article/2001290821/county-launches-vaccination-drive-against-rift-valley-fever.

35. Gachohi JM, Njenga MK, Kitala P, Bett B. Modelling Vaccination Strategies against Rift Valley Fever in Livestock in Kenya. PLoS Negl Trop Dis. 2016.

36. One Health Platform (MoH, MAAIF U and M. Uganda One Health Strategic Plan 2018-2022. [Internet]. Kampala; 2018. Available from: https://www.google.com/search?source=hp\&ei=Kok2XYTfMcqua-

vzuoAK\&q=http\%3A\%2F\%2Fhealth.go.ug\%2Fsites\%2Fdefault\%2Ffiles\%2FUganda\%25200HSP\%2520Final\%2520Launched\%25201502-2018\%2520\%25281\%2529.pdf\%3F\&oq=http\%3A\%2F\%2Fhealth.go.ug\%2Fsites\%2Fdefault\%2Ffiles\%2FU.

\section{Figures}



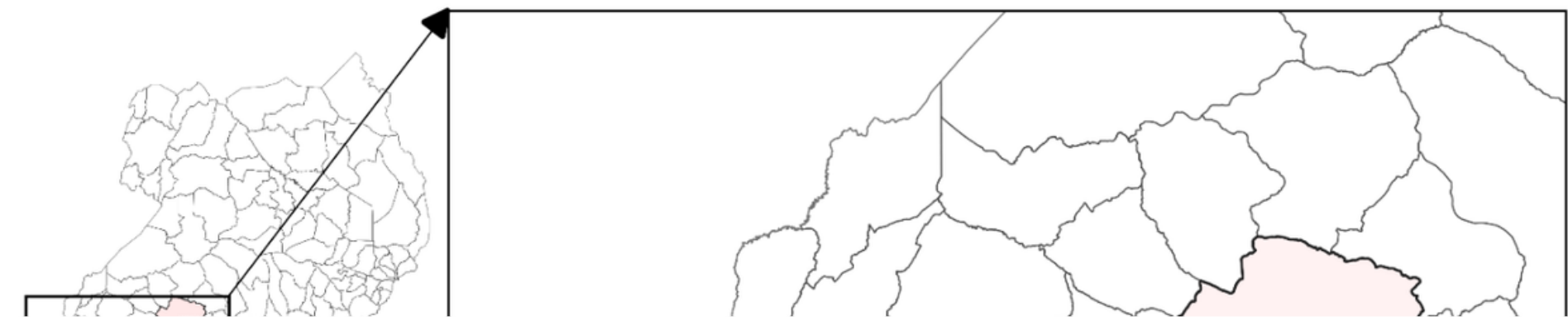

Figure 1

District-specific attack rates and number of cases for Rift Valley fever per district, Uganda, June-August 2018 


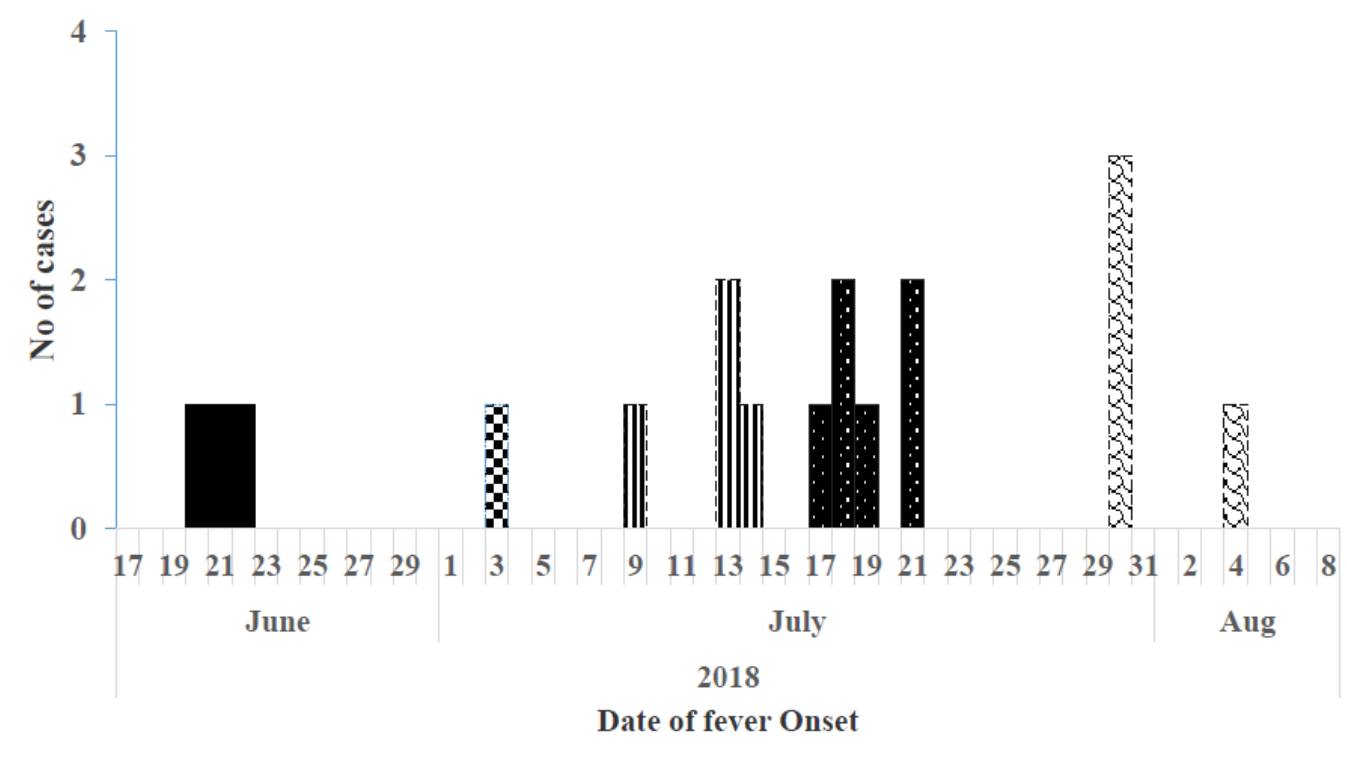

Key

- Cluster 1: Butchered meat of livestock that died suddenly on 17 June 2018 in Kasese district, Bwera market.

\$\$\# Cluster 2: Ate grilled meat of livestock that died suddenly on 29 June 2018, in Mbarara district

Cluster 3: Ate grilled meat of livestock that died suddenly on $7^{\text {th }}$ July 2018, in Ntungamo district.

Cluster 4: Butchered meat of livestock that had died suddenly on 14 July 2018, in

Sheema district

Cluster 5: Butchered meat of livestock that died of an unknown cause on 29 July 2018 in Kiruhura district

Figure 2

Epidemic curve showing the distribution of case-patients. Case-patients were reported from over 11 districts in Western and Central Uganda with the index case being reported in Kasese district in June 2018. 